\title{
Osteoporosis in Canadian adult cystic fibrosis patients: A descriptive study
} Christine Brenckmann ${ }^{\dagger 1}$, Alexandra Papaioannou* ${ }^{*} 2$, Andreas Freitag3, Rosamund Hennessey ${ }^{4}$, Suzanne Hansen ${ }^{5}$, George Ioannidis ${ }^{\dagger 6}$, Colin Webber ${ }^{\dagger 7}$ and Jonathan Adachi ${ }^{\dagger 8}$

\begin{abstract}
Address: ${ }^{1}$ Department of Community Health and Epidemiology, Dalhousie University, Halifax, (B3H 4H7), Canada, ${ }^{2}$ Department of Medicine, Hamilton Health Sciences, Hamilton, (L8N 3Z5), Canada, ${ }^{3}$ Adult Cystic Fibrosis Clinic, Hamilton Health Sciences - McMaster University Medical Centre, Hamilton, (L8N 3Z5), Canada, ${ }^{4}$ Cystic Fibrosis Clinic, Hamilton Health Sciences - McMaster University Medical Centre, Hamilton, (L8N 3Z5), Canada, ${ }^{5}$ Hamilton Health Sciences - McMaster University Medical Centre, Hamilton, (L8N 3Z5), Canada, ${ }^{6}$ Charlton Medical Centre, Hamilton, (L8N 1Y2), Canada, ${ }^{7}$ Department of Nuclear Medicine, Hamilton Health Sciences, Hamilton, (L8N 3Z5), Canada and ${ }^{8}$ Department of Medicine, St. Joseph's Hospital, McMaster University, Hamilton, (L8N 4A6), Canada

Email: Christine Brenckmann - cbrenckmann@hotmail.com; Alexandra Papaioannou* - papaioannou@hhsc.ca; Andreas Freitag - freitaga@mcmaster.ca; Rosamund Hennessey - hennessey@hhsc.ca; Suzanne Hansen - shansen@hhsc.ca; George Ioannidis - g.ioannidis@sympatico.ca; Colin Webber - webberc@mcmaster.ca; Jonathan Adachi - jd.adachi@sympatico.ca

* Corresponding author †Equal contributors
\end{abstract}

Published: 24 June 2003

BMC Musculoskeletal Disorders 2003, 4:13
Received: 09 January 2003

Accepted: 24 June 2003

This article is available from: http://www.biomedcentral.com/I47I-2474/4/13

(C) 2003 Brenckmann et al; licensee BioMed Central Ltd. This is an Open Access article: verbatim copying and redistribution of this article are permitted in all media for any purpose, provided this notice is preserved along with the article's original URL.

\begin{abstract}
Background: Cystic fibrosis is the most common fatal autosomal recessive genetic disease in the Caucasian population. Osteoporosis is increasingly being recognised as an important complication in people with cystic fibrosis.
\end{abstract}

Methods: A descriptive study of adult cystic fibrosis patients receiving care at a Canadian tertiary care hospital was conducted to evaluate the prevalence of osteoporosis, the prevalence of nonvertebral fractures, and the change in bone mineral density during the course of a year. Data on bone mineral density were obtained for 40 adult cystic fibrosis patients by reviewing dual $\mathrm{x}$-ray absorptiometry scans taken at baseline (when annual scans became standard clinical practice) and one year prior to baseline. Data on prevalent fractures were obtained by reviewing all available patient charts. Clinical and laboratory data were collected from an existing clinic database.

Results: Over half of the 40 patients had reduced T- and Z-scores at baseline. For the 27 patients who had data available one year prior to baseline, total hip and lumbar spine bone mineral density had decreased by $3.04 \%$ and $0.86 \%$ after one year while total body bone mineral density had not changed significantly. Four prior non-vertebral fractures were reported in three patients $(\mathrm{I}, \mathrm{I}, 46$ patient-years).

Conclusion: This study confirms that osteoporosis is a significant problem in adult cystic fibrosis patients, and constitutes the first published evidence of cystic fibrosis bone disease in Canadians.

\section{Background}

Cystic fibrosis (CF) is the most common fatal autosomal recessive genetic disease in the Caucasian population, affecting 30,000 Americans and about the same number 
of Europeans [1]. In the past, approximately one third of individuals with CF lived to the age of 18 and even fewer lived past the age of 30 . Today, the median survival in Canada is greater than 30 years [2]. Advances in medical science have increased life expectancy for CF patients and as a result long-term sequelae of the disease such as osteoporosis and liver disease are becoming apparent in late adolescence and into adulthood.

The etiology of osteoporosis in CF remains unknown, although factors such as corticosteroid use, vitamin D malabsorption, hypogonadism, inflammation, malnutrition, and physical inactivity are thought to be involved [3-5]. There is an increased prevalence of osteopenia and osteoporosis in CF patients compared with the general population. Studies have estimated that between 24 to $58 \%$ of adult CF patients are osteopenic [6-12].

The purpose of this descriptive study was to evaluate the prevalence of osteoporosis, the prevalence of non-vertebral fractures, and the annual change in bone mineral density (BMD) in a population of Canadian adult CF patients.

\section{Methods}

All adult CF patients aged 18 or older attending a tertiary care hospital in Hamilton, Ontario, Canada $(n=46)$ were considered for inclusion in this study. CF was diagnosed symptomatically and genetically.

Bone mineral density (BMD) was measured at the lumbar spine, femoral neck, and total hip using a Hologic QDR4500A dual $x$-ray absorptiometry (DXA) machine and was reported as gm $/ \mathrm{cm}^{2}$, T-scores (compared to the young adult peak bone mass for gender-matched controls) and Z-scores (compared to age- and gender-matched controls) for the hip, lumbar spine, and total body. According to criteria established by the World Health Organisation, a Tscore of -1.0 to -2.5 indicates osteopenia, while a T-score below -2.5 indicates osteoporosis [13]. The scanner was calibrated daily with a spine phantom to ensure all measurements were reliable. Reports were obtained from the Department of Nuclear Medicine at Hamilton Health Sciences. Data were collected for scans performed in 1999, and where available for scans performed in 1998 .

All available patient charts were reviewed to elicit all prior clinical, non-vertebral fractures (with or without trauma).

Clinical and laboratory data collected in 1999 was obtained from a clinic database, and was used to describe the study population. Dietary calcium intake was assessed by a dietitian using a combination of a 24 -hour recall and a food frequency questionnaire. Data on the cumulative use of oral corticosteroids was obtained from the clinic database, a review of all available patient records, and a review of records from the in-patient pharmacy located in the tertiary care hospital.

Paired, two-tailed, one-sample t-tests (alpha $=0.05)$ and $95 \%$ confidence intervals (CI) were used to determine whether the mean changes in BMD were significantly different from baseline.

\section{Results \\ Study Population}

DXA scans are routinely performed on all patients attending the adult CF clinic (minimum age 18 years). Of the 46 patients attending the clinic at the time of the study, six were excluded because they had no DXA scans available, either because they were new to the clinic (two), attended clinic irregularly (three) or refused to be tested (one). The study population therefore consisted of 40 patients (23 women). Three patients had received an organ transplant at the time of study (two lung, one liver). Most patients had adequate daily dietary calcium intake as estimated by a dietitian (less than $500 \mathrm{mg}$ in six patients, $500-800 \mathrm{mg}$ in three, 800-1200 mg in eleven, and more than $1200 \mathrm{mg}$ in seventeen). Four patients received daily calcium supplementation (mean [SD] 2188 [1546] mg / day), not including those receiving the calcium component of etidronate and calcium therapy for osteoporosis. The mean [SD] serum vitamin D level (taken at various times during the year) was 24.8 [13.8] ng / mL, with values ranging from one to 78. All patients received vitamin D supplementation in combination with vitamins $\mathrm{A}, \mathrm{E}$, and $\mathrm{K}$ (mean [SD] 666.7 [270.4] IUD / day). Despite supplementation, 19 patients had a vitamin D level below $25 \mathrm{ng}$ / mL. Data on past use of an oral contraceptive was available for 20 of the 23 women in the study. Twenty-one patients had received oral or intravenous corticosteroids, with a mean [SD] cumulative dose of 1659 [2793] mg and a ranging up to $14,685 \mathrm{mg}$. Fifteen women had used an oral contraceptive, eight of which were current users. The mean [SD] duration of use was 5.6 [4.2] years, and ranged from two weeks to 13 years. Seven patients had received etidronate and calcium therapy ( 90 day cyclical treatment for osteoporosis, 14 days etidronate disodium followed by 76 days of $\mathrm{CaCO}_{3}$ ). Two of the 23 women were postmenopausal, and one had received hormone replacement therapy (refer to Tables 1,2, and Figure 1).

\section{BMD at Baseline}

Over half of the 40 patients had reduced BMD at the hip and lumbar spine at baseline (Table 3). Sixteen patients $(40 \%)$ had T-scores below -1.0 at one or more sites while another eight patients $(20 \%)$ had T-scores below -2.5 at one or more sites. Twenty-three patients $(57.5 \%)$ had Zscores below -1.0 . 


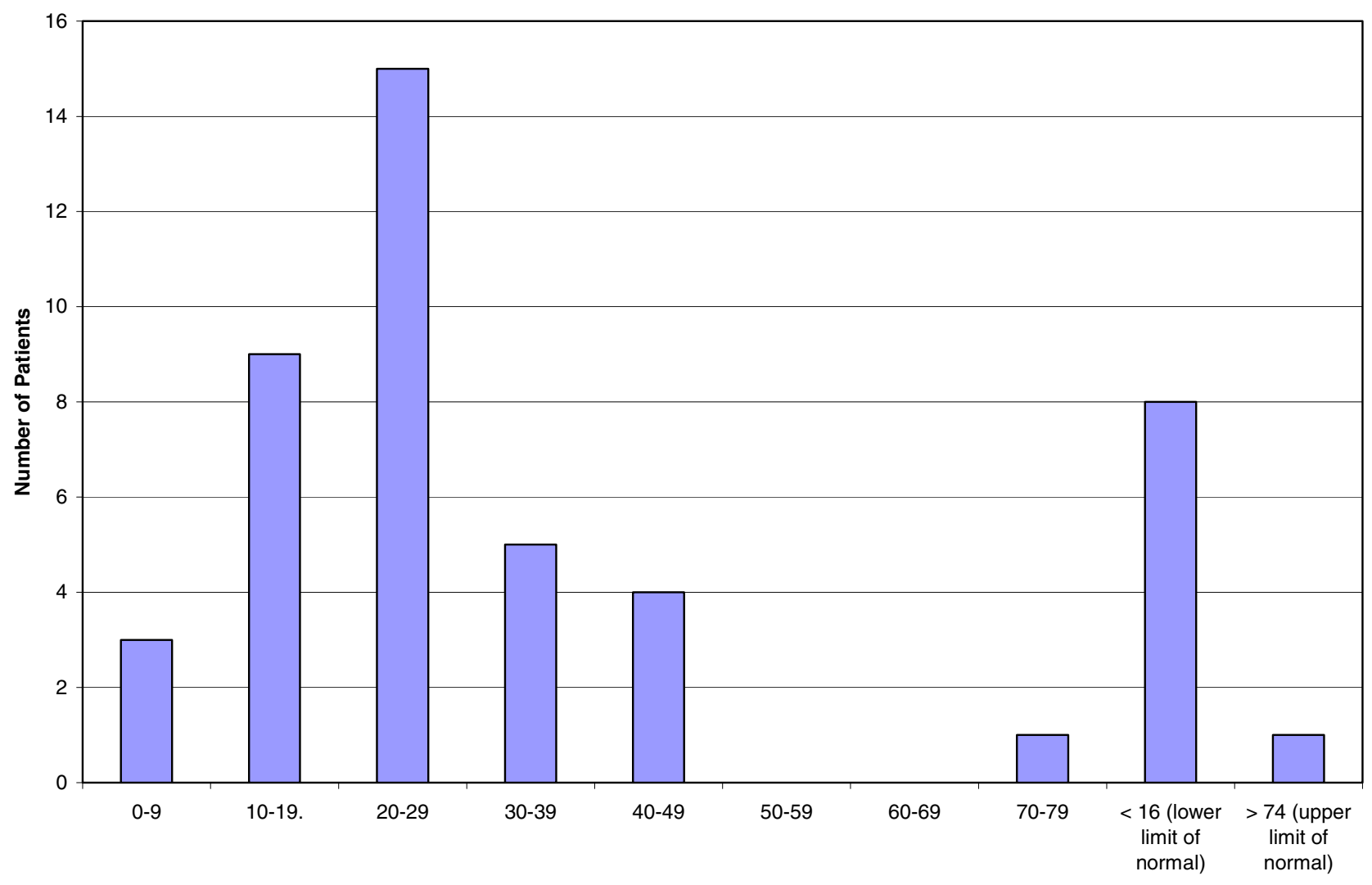

25-hydroxyvitamin D3 Levels at Baseline

Figure I

25-hydroxyvitamin D3 Levels at Baseline for 37 Adult CF Patients

\section{Annual Changes in BMD}

Previous DXA scans were available for 27 of the 40 patients. The change in BMD from the previous year to baseline demonstrated a decrease at the hip (left hip $3.01 \%, 95 \%$ CI -4.76 to -1.26 ; right hip $-3.06 \%$, 95\% CI 4.69 to -1.43$)$ and lumbar spine $(-0.86 \%, 95 \%$ CI -2.46 to $0.75)$. Twenty-one of these patients had whole body scans on both occasions. The annual change in total body BMD was negligible $(0.0 \%$, SD $1.4 \%)$.

\section{Sub-Group Analysis}

While the sample size was too small for any adequately powered sub-group analyses, a description of patients receiving bisphosphonates is presented here. With regard to bisphosphonate use, seven patients (aged 21-48, two males) had been prescribed therapy with etidronate. At baseline, these seven patients were all osteoporotic at the lumbar spine and hip. One patient had undergone a lung transplant, one was awaiting lung transplant, and one had undergone a liver transplant. One of the women had reached menopause at age 32. All seven had received oral corticosteroids, ranging from $350-3650 \mathrm{mg} /$ year. Four patients had a dietary calcium intake greater than 1200 mg per day, and all were receiving vitamin D supplementation. The mean [SD] duration of therapy was 269 [89.9] days and ranged from 90-344 days. Over this short period of time, there was a mean increase in total body BMD $(11.8 \%$, SD 5.6) and a mean decrease at the hip (-3.5\%, SD 3.9) and lumbar spine (mean -1.6\%, SD 6.8). These differences were not statistically significant. 
Table I: Clinical Characteristics at Baseline for $\mathbf{4 0}$ Adult CF Patients

\begin{tabular}{|c|c|c|c|}
\hline Variable & Mean [SD] & Range & $\mathrm{n}$ \\
\hline Age (years) & $28.7[8.4]$ & $19-52$ & 40 \\
\hline Age at first menstruation (years) & $12.9[1.5]$ & $11-16$ & 17 \\
\hline Height $(\mathrm{cm})$ & I $66.4[8.4]$ & $150-183$ & 38 \\
\hline Weight $(\mathrm{kg})$ & $57.4[8.0]$ & $43.3-78$ & 38 \\
\hline Body mass index $\left(\mathrm{gm} / \mathrm{kg}^{2}\right)$ & $20.6[2.3]$ & $16.6-25.1$ & 37 \\
\hline $\mathrm{VO}_{2} \max (\mathrm{L} / \mathrm{min})^{\prime}$ & $1.7[0.6]$ & $0.65-2.65$ & 37 \\
\hline $\mathrm{VO}_{2} \max (\%$ normal $)$ & $87.9[23.4]$ & $37-117$ & 37 \\
\hline $\operatorname{FEV}_{1}(L)^{2}$ & $1.9[0.6]$ & $0.7-3.3$ & 37 \\
\hline $\mathrm{FEV}_{\mathrm{l}}(\%$ normal) & $52.3[15.7]$ & $22-87$ & 37 \\
\hline $\mathrm{DLCO}(\mathrm{mL} / \mathrm{min} / \mathrm{mmHg})^{3}$ & $19.8[6.5]$ & $2.05-34.2$ & 37 \\
\hline DLCO (\% normal) & $60.0[11.6]$ & $40-85$ & 37 \\
\hline Exercise capacity $(\mathrm{kpm})^{4}$ & $797.3[237.4]$ & $400-1300$ & 37 \\
\hline Exercise capacity (\% normal) & $76.6[20.4]$ & $41-113$ & 37 \\
\hline Genotype & - & - & \\
\hline homozygous $\Delta \mathrm{F} 508$ & & & 12 \\
\hline heterozygous $\Delta \mathrm{F} 508$ & & & 18 \\
\hline other heterozygous & & & 5 \\
\hline unknown & & & 5 \\
\hline
\end{tabular}

$\mathrm{I} \mathrm{VO}_{2} \mathrm{max}=$ oxygen consumption during controlled exercise; ${ }^{2} \mathrm{FEV},=$ forced expiratory volume in one second; ${ }^{3} \mathrm{DLCO}=$ diffusion of lung (carbon monoxide); ${ }^{4}$ exercise capacity $=$ a measure of power output; measured using Stage I Jones protocol

Table 2: Laboratory Values at Baseline for $\mathbf{4 0}$ Adult CF Patients

\begin{tabular}{|c|c|c|c|c|c|}
\hline Variable & Mean [SD] & Range & $\mathrm{n}$ & $\begin{array}{l}\text { \# of Patients Below } \\
\text { Normal Range }\end{array}$ & $\begin{array}{l}\text { \# of Patients Above } \\
\text { Normal Range }\end{array}$ \\
\hline $\begin{array}{l}\text { 25-hydroxyvitamin } \mathrm{D}_{3}(\mathrm{ng} / \mathrm{mL}) \text {; normal range } \\
16-74 \mathrm{ng} / \mathrm{mL} *\end{array}$ & $24.8[13.8]$ & $\mathrm{I}-78$ & 37 & 8 & 1 \\
\hline $\begin{array}{l}\text { Calcium (mmol / L); normal range 2.20-2.58 } \\
\mathrm{mmol} / \mathrm{L}\end{array}$ & $2.3[0.1]$ & $2.01-2.56$ & 36 & 1 & 0 \\
\hline $\begin{array}{l}\text { Phosphate (mmol / L); normal range 0.80-I.45 } \\
\mathrm{mmol} / \mathrm{L}\end{array}$ & $1.2[0.2]$ & $0.72-1.58$ & 37 & 0 & 4 \\
\hline $\begin{array}{l}\text { Parathyroid hormone }(\mathrm{pg} / \mathrm{mL}) \text {; normal range } \\
10-65 \mathrm{pg} / \mathrm{mL}\end{array}$ & $54.6[80.0]$ & $14-360$ & 17 & 0 & 2 \\
\hline $\begin{array}{l}\text { Total alkaline phosphatase (IU / L); normal } \\
\text { range } 50-120 \mathrm{IU} / \mathrm{L}\end{array}$ & I 20.7 [78.3] & $49-490$ & 37 & 1 & 11 \\
\hline $\begin{array}{l}\text { Gamma-glutamyl aminotransferase (IU / L); } \\
\text { normal < } 45 \mathrm{IU} / \mathrm{L}\end{array}$ & 34.7 [39.5] & $6-140$ & 36 & 0 & 9 \\
\hline
\end{tabular}

* taken at various times during the year

\section{Fractures}

Four prior clinical, non-vertebral fractures had been reported for three patients $(7.5 \%$, two women). This corresponds to 0.35 fractures per 100 patient-years over 1,146 patient-years. Clearly, the small number of fractures means there is considerable uncertainty associated with this estimate of fracture prevalence. One patient (male) had fractured a clavicle, although the mechanism of the fracture was not recorded. A second patient had fractured the fourth cervical spine and nose in a car accident. The final individual had an atraumatic hip fracture while hospitalised and awaiting transplant.

\section{Discussion \\ BMD at Baseline}

More than half of adult CF patients in this study had low BMD compared to BMD reference populations ( $\mathrm{Z}$ - and Tscores).

This observation supports previous studies of osteoporosis in people with CF. A longitudinal study of 151 adult CF patients aged 15 to 52 [6] showed that $34 \%$ of patients had a Z-score of - 2 or less at any site. Additional studies of osteoporosis in CF report a prevalence of osteopenia ranging from $24-58 \%$ and a prevalence of osteoporosis rang- 
Table 3: Mean BMD at Baseline for 40 Adult CF Patients

\begin{tabular}{|c|c|c|c|c|c|c|c|c|c|}
\hline & \multicolumn{3}{|c|}{$\mathrm{gm} / \mathrm{cm}^{2}$} & \multicolumn{3}{|c|}{ t-score } & \multicolumn{3}{|c|}{ z-score } \\
\hline & mean [SD] & range & $\mathrm{n}$ & mean [SD] & range & $\mathrm{n}$ & mean [SD] & range & $\mathrm{n}$ \\
\hline total body & $\mathrm{I} .2[0.1]$ & 0.93 to 1.44 & 37 & - & - & - & - & - & - \\
\hline left hip & $0.9[0.2]$ & 0.61 to 1.21 & 40 & $-1.0[1.1]$ & -3.45 to 1.55 & 40 & $-0.9[1.1]$ & -3.32 to 1.01 & 36 \\
\hline right hip & $0.9[0.1]$ & 0.62 to 1.12 & 39 & $-1.0[1.1]$ & -3.45 to 1.25 & 40 & $-1.0[1.1]$ & $-3.3 \mid$ to 1.28 & 36 \\
\hline lumbar spine & $0.8[0.1]$ & 0.67 to 1.13 & 39 & $-1.2[1.2]$ & -3.46 to 1.87 & 40 & $-1.1[1.3]$ & -3.30 to 2.72 & 40 \\
\hline
\end{tabular}

ing from 4-76\% [7-12]. Heterogeneity in age, corticosteroid use, organ transplantation, and other risk factors may account for this large variation. The prevalence of low BMD in CF patients may represent decreased bone building, increased bone resorption [3], or both [14].

\section{Annual Changes in BMD}

This paper provides important information on longitudinal changes in BMD. Patients with a DXA scan one year prior to baseline assessment showed a mean decrease in $\mathrm{BMD}$ at the hip and lumbar spine, while total body BMD remained stable. These 27 patients represent a skewed sample since they underwent dual x-ray absorptiometry scans because of active referral rather than standard clinical practice. The majority of these patients had received or were receiving treatment with etidronate or oral corticosteroids, therefore these data do not represent the natural progression of bone loss in people with cystic fibrosis. It is interesting to note that CF patients were more likely to lose $\mathrm{BMD}$ at the hip than at the spine, possibly due to calcium and vitamin D deficiency [15]. The decrease in bone mass may have been caused by the use of oral corticosteroids [16]. There is a need to determine whether these changes are clinically significant. A review of patient charts revealed no significant changes in height. This was not surprising since the study population consisted of adults who were not actively fracturing. There were some fluctuations in weight over the one year prior to baseline. A limited sub-group analysis of etidronate plus calcium used by five patients for between 90 and 344 days showed a non-significant increase in total body BMD and a nonsignificant decrease in $\mathrm{BMD}$ at the hip and lumbar spine. Given the small sample size of this sub-group, the variation in response, and the variation in duration of therapy it is difficult to determine the clinical effect of etidronate plus calcium on osteoporosis in patients with cystic fibrosis.

Three published studies have examined the annual progression of osteoporosis in CF patients. Bhudhikanok and colleagues [17] examined 21 adult CF patients (15 females) with a mean age of 27 years and found no statis- tically significant annual changes at the lumbar spine, femoral neck, and total body. A study of 153 adult CF patients (70 females) aged 15-52 [6] found an annual increase (standard deviation) of $0.9 \%(4.0 \%, \mathrm{p}=0.032)$ at the distal forearm and $0.1 \%(4.6 \%, \mathrm{p}=\mathrm{ns})$ at the ultradistal forearm as measured by single $\mathrm{x}$-ray absorptiometry. This same study found an annual decrease of $0.4 \%(4.3 \%, \mathrm{p}=\mathrm{ns})$ at the lumbar spine and $1.8 \%(3.6 \%$, $\mathrm{p}<0.001)$ at the total hip as measured by DXA. The authors published a subsequent report of 114 adult patients [18]. In patients aged 24 years or younger $(\mathrm{n}=$ $55)$, there was a mean annual increase of $2.9 \%$ (95\% CI $1.6 \%$ to $4.2 \%$ ) at the distal forearm, but a mean annual decrease of $2.5 \%$ (95\% CI $-3.8 \%$ to $-1.2 \%$ ) at the femoral neck and a decrease of $2.2 \%$ (95\% CI $-3.3 \%$ to $-1.0 \%$ ) for the total hip ( $\mathrm{p}<0.001$ for all analyses). In patients aged 25 years or older $(n=59)$, there was a mean annual decrease of $0.8 \%$ (95\% CI -1.5 to $-0.1 \%, \mathrm{p}=0.026)$ at the distal forearm, a decrease of $1.9 \%$ (95\% CI $-2.9 \%$ to $0.8 \%, \mathrm{p}<0.001)$ at the femoral neck, and a decrease of $1.5 \%(95 \%$ CI $-2.4 \%$ to $-0.6 \%, \mathrm{p}=0.001)$ for the total hip.

\section{Fractures}

Three patients had four prior non-vertebral fractures. This represents a smaller fracture rate than reported in the literature, although this study is limited by a small sample size and a small number of patient-years of follow-up. Note that this study only examined the incidence of clinical non-vertebral fractures.

Aris et al [7] studied fractures in 70 adult CF patients referred for lung transplantation, a population with a higher risk of fractures than the patients in this study. The rate of clinical, non-vertebral fractures in men aged 25-45 years was 8.5 per 100 patient-years compared to a population rate of $2.8(\mathrm{p}<0.05)$. The rate was slightly lower in women aged 16-34 years: 3.7 fractures per 100 patientyears compared to 1.7 in the general population ( $\mathrm{p}<$ $0.05)$. Vertebral compression and rib fractures were 100and 10 -fold more common than predicted $(\mathrm{p}<0.001)$, respectively. Haworth et al [6] found a history of fracture in 51 of the 151 patients aged 15-52. Since a greater sample size is required to generate meaningful data, no con- 
clusions about the prevalence of fractures in CF patients can be drawn from this study.

\section{Laboratory Values}

Despite vitamin $\mathrm{D}_{3}$ supplementation in the form of a fatsoluble multivitamin, there was a high prevalence of vitamin D deficiency (refer to Table 2 and Figure 1). Nineteen patients had serum vitamin D levels below $25 \mathrm{ng} / \mathrm{mL}$, the lower limit of normal. Deficiency is not unexpected given the latitude of the treatment centre, and given that vitamin $\mathrm{D}$ levels were measured at various times during the year and are therefore sensitive to seasonal variation [19]. One patient had elevated total alkaline phosphatase (AP) and parathyroid hormone (PTH) levels and was vitamin $\mathrm{D}$ deficient, indicating possible osteomalacia or hyperparathyroidism rather than osteoporosis. An additional five patients had elevated total AP and gamma-glutamyl aminotransferase (GGT) levels, which indicates possible liver disease. Note that GGT levels are normally a measure of liver function and usually not associated with osteoporosis. Six patients had elevated total AP levels with normal PTH and GGT levels, a profile that could represent either osteoporosis or biliary obstruction.

\section{Study Limitations}

This study is limited by a relatively small sample size, but is a pilot for a larger study to be conducted in the future. Patients with established osteoporosis were more likely to have had at least two DXA scans, therefore data on annual changes in BMD may reflect changes in patients with more severe bone disease. Data on clinical, non-vertebral fractures relied on all available patient charts, while data on vertebral fractures were unavailable. Information on hormonal levels was not available. Data were not stratified by patient characteristics such as etidronate use, corticosteroid use, or gender. Regression will be conducted in subsequent studies with larger sample size.

\section{Conclusions}

This study confirms that osteoporosis is a significant problem in adult CF patients. Since all previous studies were conducted in the USA or the UK, this study provides data from a Canadian context. Additional studies are warranted to further describe annual changes in BMD and to determine what magnitudes of change in BMD are clinically relevant.

\section{List of Abbreviations}

AP alkaline phosphatase

BMD bone mineral density

CF cystic fibrosis

CI confidence interval
DXA dual x-ray absorptiometry

GGT gamma-glutamyl aminotransferase

PTH parathyroid hormone

SD standard deviation

\section{Competing interests}

None declared.

\section{Authors' contributions}

$\mathrm{CB}$ conducted the research under the supervision of $\mathrm{AP}$ and the clinicians at the Adult Cystic Fibrosis Clinic (AF, $\mathrm{RH}, \mathrm{SH}$ ). All authors provided expert advice on data analysis and manuscript preparation.

\section{Acknowledgements}

Nicole Ferko helped with editing and co-ordination, and Mirela Mrkonjic provided assistance with manuscript preparation.

\section{References}

I. Yankaskas JR, Knowles MR and eds: Cystic fibrosis in adults Philadelphia, Lippincott-Raven 1999.

2. Brennan $A L$ and Geddes DM: Cystic fibrosis Curr Opin Infect Dis 2002, I 5(2): $175-182$

3. Haworth CS, Selby PL, Webb AK and Adams JE: Osteoporosis in adults with cystic fibrosis J R Soc Med I 998, 9 I (Suppl 34): | 4- I8.

4. Ott SM and Aitken ML: Osteoporosis in patients with cystic fibrosis Clin Chest Med 1998, 19:555-567.

5. Lambert JP: Osteoporosis: A new challenge in cystic fibrosis Pharmacotherapy 2000, 20:34-5I.

6. Haworth CS, Selby PL, Webb AK, Dodd ME, Musson H, McNiven R, Economou G, Horrocks AW, Freemont AJ and Mawer EB et al.: Low bone mineral density in adults with cystic fibrosis Thorax 1999, 54:961-967.

7. Aris RM, Renner JB, Winders AD, Buell HE, Riggs DB, Lester GE and Ontjes DA: Increased rate of fractures and severe kyphosis: Sequelae of living into adulthood with cystic fibrosis Ann Intern Med 1998, I 28:186-193.

8. Grey AB, Ames RW, Matthews RD and Reid IR: Bone mineral density and body composition in adult patients with cystic fibrosis Thorax 1993, 48:589-593.

9. Bachrach LK, Loutit CW and Moss RB: Osteopenia in adults with cystic fibrosis Am J Med 1994, 96:27-34.

10. Bhudhikanok GS, Lim J, Marcus R, Harkins A, Moss RB and Bachrach LK: Correlates of osteopenia in patients with cystic fibrosis Pediatrics 1996, 97:103-111.

II. Laursen EM, Mølgaard C, Michaelsen KF, Koch C and Muller J: Bone mineral status in 134 patients with cystic fibrosis Arch Dis Child | 999, 8 | :235-240.

12. Elkin SL, Fairney A, Burnett S, Kemp M, Kyd P, Burgess J, Compston JE and Hodson ME: Vertebral deformities and low bone mineral density in adults with cystic fibrosis: A cross-sectional study Osteoporos Int 200 I, I 2:366-372.

13. Kanis JA: Osteoporosis Oxford, Blackwell Science 1994.

14. Bachrach L: Osteopenia in CF: Too little gain? Too much loss? Lecture W20b presented at the I3th Annual North American CF Conference, Seattle, WA. October 7-10 1999

15. McGuigan FE, Murray L, Gallagher A, Davey-Smith G, Neville CE, Van't Hof R, Boreham $C$ and Ralston SH: Genetic and environmental determinants of peak bone mass in young men and women J Bone Miner Res 2002, I 7: I 273-I 279.

16. Yeap SS and Hosking DJ: Management of corticosteroidinduced osteoporosis Rheumatology 2002, 4I: I088- 094.

17. Bhudhikanok GS, Wang MC, Marcus R, Harkins A, Moss RB and Bachrach LK: Bone acquisition and loss in children and adults with cystic fibrosis: A longitudinal study J Pediatr 1998, I33: I827. 
18. Haworth CS, Selby PL, Horrocks AW, Mawer EB, Adams JE and Webb AK: A prospective study of change in bone mineral density over one year in adults with cystic fibrosis Thorax 2002, 57:719-723.

19. Rucker D, Allan JA, Fick GH and Hanley DA: Vitamin D insufficiency in a population of healthy western Canadians CMAJ 2002, 166:1517-1524.

\section{Pre-publication history}

The pre-publication history for this paper can be accessed here:

http://www.biomedcentral.com/1471-2474/4/13/prepub

Publish with Bio Med Central and every scientist can read your work free of charge

"BioMed Central will be the most significant development for disseminating the results of biomedical research in our lifetime. "

Sir Paul Nurse, Cancer Research UK

Your research papers will be:

- available free of charge to the entire biomedical community

- peer reviewed and published immediately upon acceptance

- cited in PubMed and archived on PubMed Central

- yours - you keep the copyright

Submit your manuscript here:

http://www.biomedcentral.com/info/publishing_adv.asp 